\title{
Initial results of combining GPS occultations with ECMWF global analyses within a 1DVar framework
}

\author{
E. Robert Kursinski ${ }^{1 *}$, Sean B. Healy ${ }^{2}$, and Larry J. Romans ${ }^{1}$ \\ ${ }^{1}$ MS 238-600 Jet Propulsion Laboratory, California Institute of Technology, Pasadena, CA 91109-8099, U.S.A. \\ ${ }^{2}$ Numerical Weather Prediction Division (Room 338), The Met Office, London Road, Bracknell RG12 2SZ, U.K.
}

(Received January 20, 2000; Revised August 28, 2000; Accepted August 28, 2000)

\begin{abstract}
We present results of combining occultation refractivity profiles from GPS/MET with ECMWF global analyses in a 1DVar framework in order to separate the wet and dry contributions to refractivity and assess their impact on the analyzed temperature, surface pressure and specific humidity fields. We find significant zonal mean temperature, surface pressure and humidity differences between the 1DVar solutions and the ECMWF analyses reflecting biases between the GPS refractivities and ECMWF analyses. Large profile-to-profile temperature discrepancies in the tropical lower stratosphere are due to waves not represented in the analyses. The 1DVar solution is generally drier than ECMWF particularly in the southern subtropics. Lack of moisture above $300 \mathrm{hPa}$ in the present model caused the solution to make large adjustments in low latitude surface pressure and tropospheric temperatures to increase upper troposphere densities and compensate for the missing upper level moisture. The discrepancies between the solution and the background and observational data sets represent roughly a 2-sigma level of agreement rather than the 1-sigma level desired in a 1DVar solution. Given the simplicity of our error covariances, our results are promising as a first step. In the future, the error covariances need to be refined and, in particular, to vary with location.
\end{abstract}

\section{Introduction}

We describe a set of initial results of combining GPS occultation refractivity profiles with a set of ECMWF global weather analyses in a 1D variational (1DVar) assimilation scheme. The occultations, which number approximately 800, were acquired by GPS/MET from June 21 to July 4, 1995. One goal here is to derive temperature and moisture profiles from the GPS results using the ECMWF analyses as background information to provide the constraints needed to separate the wet and dry contributions to the refractivity which GPS measures. Alternatively one can view the purpose of this effort as using GPS observations to improve weather analyses. Ultimately this work represents a step toward combining the unique features of the GPS observations with other observations and modeling to improve weather forecasting and analyses and our understanding of the behavior of our climate system.

\section{GPS Occultation Background}

The GPS to low-Earth-orbiter (LEO) occultation geometry is shown in Fig. 1. Relative motion between the transmitter and receiver produce a limb scan of the atmosphere in roughly 60 seconds. From measurements of Doppler shift and knowledge of the viewing geometry, the bending angle, $\alpha$, and asymptotic miss distance, $a$, are derived. The index of refraction, $n$, as a function of radius from the center of

*Now at Department of Atmospheric Science, University of Arizona, P.O. Box 210081, Tucson, AZ 85721-0081, U.S.A.

Copy right (c) The Society of Geomagnetism and Earth, Planetary and Space Sciences (SGEPSS); The Seismological Society of Japan; The Volcanological Society of Japan; The Geodetic Society of Japan; The Japanese Society for Planetary Sciences. curvature, $r$, is derived from $\alpha(a)$ via an Abelian integral transform relation under the assumption of local spherical symmetry (Fjeldbo et al., 1971). At microwave wavelengths refractivity (defined as $N=[n-1] 10^{6}$ ) is given as

$$
N=b_{1} \frac{P}{T}+b_{2} \frac{P_{w}}{T^{2}}
$$

where $P$ is pressure, $P_{w}$ is partial pressure of water vapor, $T$ is temperature and $b_{1}$ and $b_{2}$ are constants equal to 77.6 $\mathrm{K} \mathrm{hPa}^{-1}$ and $3.73 \times 10^{5} \mathrm{~K}^{2} \mathrm{hPa}^{-1}$ respectively. Because of its permanent dipole moment, each water vapor molecule contributes approximately 15 to 20 times the refractivity of an average dry $\left(\mathrm{N}_{2}\right.$ or $\left.\mathrm{O}_{2}\right)$ molecule and water therefore contributes significantly to refractivity in the lower troposphere. In the cold, dry conditions of the upper troposphere and above $(T<230 \mathrm{~K})$ water contributes little to refractivity and profiles of refractivity are directly proportional to density. Hydrostatically integrating density yields a profile of pressure (or equivalently geopotential), and knowing density and pressure yields temperature. Given additional temperature information, water vapor can be derived in the middle and lower troposphere.

Coverage and Resolution: A single orbiting GPS receiver with fore and aft antennas can observe between 500 and 700 daily occultations distributed globally, a number which can be roughly doubled by adding a GLONASS receive capability. NASA's GPS Earth Observatory (GEO) will consist of several orbiting GPS occultation receivers by the end of 2000 including, CHAMP, SAC-C and IOX which will produce more than 1000 occultations per day rivaling the present global radiosonde network but with far more even distribution of coverage. The limb-viewing geometry of the 


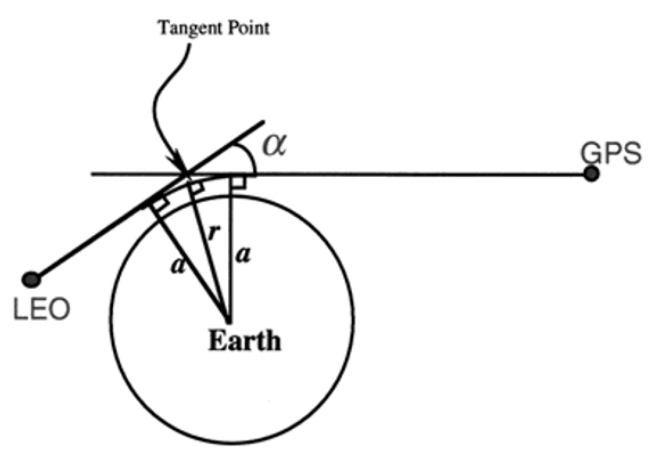

Fig. 1. Occultation geometry.

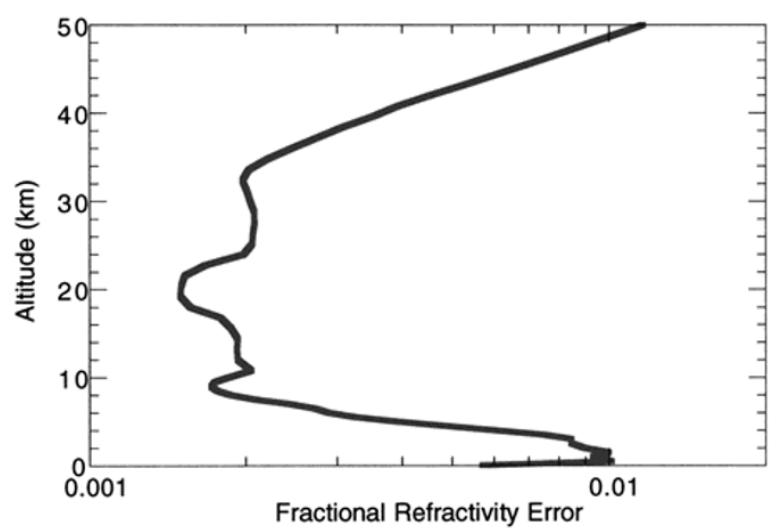

Fig. 2. Square root of diagonal terms of the measurement fractional refractivity error covariances.

occultation observations creates a pencil-like sampling volume with along-track resolution of order $200-300 \mathrm{~km}$ vertical and cross-track resolution of order $1 \mathrm{~km}$ or better as defined by Fresnel diffraction. Sub-Fresnel resolution is achievable through reduction of diffraction effects (Karayel and Hinson, 1997).

Predicted Accuracy: Figure 2 shows the expected fractional refractivity errors versus height based on a detailed examination of refractivity, temperature and pressure errors by Kursinski et al. (1997). Fractional temperature and pressure errors are similar yielding sub-Kelvin temperature and $\sim 10 \mathrm{~m}$ geopotential height accuracies from the upper troposphere into the lower stratosphere. Horizontal gradients are the dominant refractivity error source near the surface and are primarily responsible for the increasing fractional error at lower altitudes. GPS/MET temperatures are consistent with the ECMWF analyses at the 1 to $1.5 \mathrm{~K}$ level (Kursinski et al., 1996; Rocken et al., 1997) while geopotential comparisons with ECMWF are consistent at the $20 \mathrm{~m}$ level (Leroy, 1997). Kursinski et al. (1995) and Kursinski and Hajj (2000a) estimated the RMS accuracy of water vapor profiles derived from GPS refractivity profiles to be $0.2 \mathrm{~g} / \mathrm{kg}$ in drier regions increasing to $0.5 \mathrm{~g} / \mathrm{kg}$ in wetter regions with of the order of $0.1 \mathrm{~g} / \mathrm{kg}$ depending on the accuracy of assumed temperature.

\section{1DVar Retrieval Overview}

Here we briefly summarize the 1D variational approach used in this study. For further details see Healy and Eyre (2000). In a variational retrieval, the most probable atmospheric state, $x$, is calculated by combining a priori (or background) atmospheric information, $x^{b}$, with the measurements/observations, $y^{o}$, in a statistically optimal way. The solution, $x$, gives the best fit-in a least squared senseboth the observations and a priori information. It can be shown in the case of Gaussian error distributions, that obtaining the most probable state is equivalent to minimizing a cost function $J(x)$ given by,

$$
\begin{aligned}
J(x)= & \frac{1}{2}\left(x-x^{b}\right)^{T} B^{-1}\left(x-x^{b}\right) \\
& +\frac{1}{2}\left(y^{o}-H(x)\right)^{T}(E+F)^{-1}\left(y^{o}-H(x)\right)
\end{aligned}
$$

where $B$ is the expected background error covariance matrix; $H(x)$ is the forward model, mapping the atmospheric information $x$ into measurement space; $E$ and $F$ are the expected error covariances of measurements and forward model respectively. The superscripts $T$ and -1 denote matrix transpose and inverse. Note that the normalized form has allowed us to combine "apples" (an atmospheric model state vector) and "oranges" (GPS observations of bending angles or refractivity). The error covariance of the solution, $x$, is

$$
B^{\prime}=\left[B^{-1}+K^{T}(E+F)^{-1} K\right]^{-1}
$$

where $K$ is $\nabla_{x} y^{o}$, the gradient of $y^{o}$ with respect to $x$.

Implementation: In this analysis, the measurement vector, $y^{o}$, is a one dimensional vertical profile of refractivity as a function of geopotential height $\left(y_{m}^{o}=N\left(z_{m}\right)\right)$, at a fixed tangent point location. With GPS occultations, $y^{o}$ could consist of bending angles or refractivity. Although using refractivity derived via the Abel transform is not as accurate because of the spherical symmetry approximation, it is much simpler than use of bending angles which requires a more complicated forward operator. The background state vector, $x^{b}$, is a profile extracted from global analyses available every 6 hours from the European Centre for Medium-range Weather Forecasts (ECMWF), derived by interpolating the model fields to the locations of the occultation tangent points and extracting the vertical profile information. It contains 46 elements: 30 temperature values on fixed pressure levels $\left(T_{i}=T\left(P_{i}\right)\right)$ between 1000-10 hPa, $15 \ln$ (specific humidity $(\mathrm{g} / \mathrm{kg}))\left(\ln Q_{i}=\ln Q\left(P_{i}\right)\right)$ values on the lowest 15 levels (between 1000-300 $\mathrm{hPa}$ ) and the surface pressure. Note that the $\ln Q$ values are zero at altitudes above the $300 \mathrm{hPa}$ level, which turns out to have important consequences as we will discuss in Section 5. The background covariance matrix, $B$, is based on a subset of that used in the operational processing of TOVS data at UKMO (Gadd et al., 1995) and includes a full covariance structure. The temperature and specific humidity errors from the diagonal terms of the background error covariance matrix are shown in Figs. 3 and 4 respectively. Relatively large temperature errors near $200 \mathrm{hPa}$ reflect the uncertainties near the northern mid-latitude tropopause. The diagonal error term associated with the surface pressure is $2.5 \mathrm{hPa}$. 


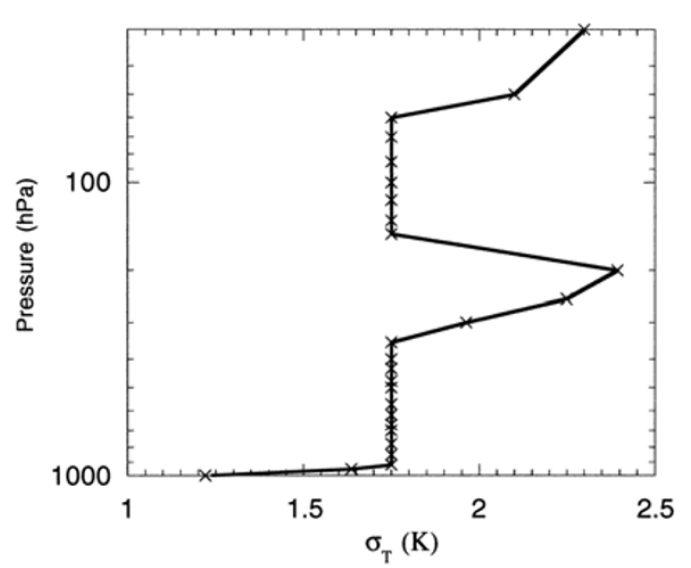

Fig. 3. Square root of diagonal terms of temperature error covariances.

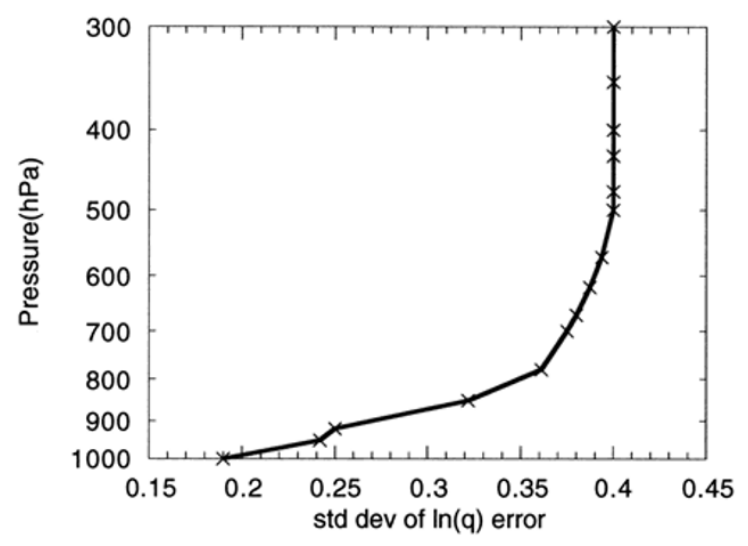

Fig. 4. Square root of diagonal terms of specific humidity error covariances.

The forward model: $H\left(x^{n}\right)$ : The forward model ' $H$ ' evaluates a model refractivity value, $N$, for each 'observed' geopotential height, $z_{m}$, using the current state vector estimate, $x^{n}$. The derivation of the refractivity profile from state vector is composed of the following steps. Firstly, the virtual temperature on the fixed pressure levels is calculated. The hydrostatic equation is then integrated, assuming the virtual temperature varies linearly with geopotential height between the pressure levels which enables evaluation of the gradients of $\log$ (specific humidity), temperature and virtual temperature with respect to geopotential height. The specific humidity, temperature and pressure values can then be calculated at an observation geopotential height, $z_{m}$. This formulation of the model ensures that the refractivity, pressure, temperature and humidity are continuous over the vertical profile.

Observation Errors: The refractivity measurement error covariance matrix, $E$, is estimated from Fig. 2. The variance values, $\sigma_{m}^{2}$, are calculated assuming the percentage error in the refractivity is $1 \%$ at the surface and falls linearly with height to $0.2 \%$ at $10 \mathrm{~km}$ above which the percentage error is constant at this value to $35 \mathrm{~km}$ altitude $(\sim 10 \mathrm{hPa})$. Since the discrete form of the Abel transform is simply a weighted sum of the bending angle values, vertical correlations exist between the refractivity values such that the off-diagonal terms of $E, E_{n m}$, are non-zero even if the bending angle er- rors are uncorrelated. In this work, these are approximated assuming an exponential decay with separation in geopotential height given by, $E_{n m}=\sigma_{n} \sigma_{m} \exp \left(-l\left(z_{n}-z_{m}\right)\right)$ where $l$ is the inverse of a scale length with a numerical value of chosen to be $3 \times 10^{-4} \mathrm{~m}^{-1}$. This model has been compared with covariances evaluated from the impulse response of an Abel transform routine with the assumption of uncorrelated bending angle errors, and it shows reasonable agreement.

Forward model errors: The forward model in this case is simply the refractivity equation (1) plus the interpolation from the model pressure levels to the observational geopotential height levels. The dry part of (1) is accurate to $0.02 \%$ and the wet part is accurate to $\sim 1 \%$ (Kursinski et al., 1997). In comparison to other sources of error, these contributions are small and can therefore be ignored. The approach used to interpolate from model pressure levels to observed geopotential heights is very accurate and the interpolation errors will be small to the extent that the model levels are spaced sufficiently close to represent the atmospheric structure captured by the observations. Issues regarding model representativeness (how well can the model actually represent the behavior captured in the observations), and vertical resolution sufficient to capture the important aspects of the observations are discussed by Kursinski et al. (2000). For the purposes of the present study, since the errors in the forward model are small, we have set the $F$ matrix to 0 .

\section{1DVar Results Using GPS/MET Data}

We have combined refractivity profiles derived from GPS/MET occultation observations from June 21 to July 4, 1995 with background state vectors from the nearest 6hour ECMWF analysis, interpolated to the location of each occultation. The data period was chosen because the GPS Anti-Spoofing (AS) encryption was off and the software in the GPS/MET receiver during this period enabled the profiles to extend to within $1 \mathrm{~km}$ of the surface much of the time.

We discuss the 1DVar results in terms of temperature, surface pressure, and specific humidity differences between the background and solution and in terms of refractivity differences between the observations and solution. The differences are characterized by the mean and standard deviation of their zonal (latitude versus height) behavior.

\subsection{DVar temperature results}

Near the surface, the small size of the mean solution minus background $(\mathrm{S}-\mathrm{B})$ temperature differences in Fig. 5 reflects the relatively small background temperature error at 1000 $\mathrm{hPa}$ (Fig. 3) and the limited number of occultations penetrating all the way to the surface. Above the surface, there are significant differences between the solution and background temperature due to the refractivity observations. The solution is significantly warmer than the background $(\mathrm{S}-\mathrm{B}>0)$ in the low-latitude, lower troposphere between $65 \mathrm{~S}$ and $60 \mathrm{~N}$ and in the low latitude, near-tropopause region as well as near $50 \mathrm{hPa}$ near $20 \mathrm{~S}$ and $30 \mathrm{~N}$. Much of the Northern Hemisphere north of $60 \mathrm{~N}$ and the Southern Hemisphere south of 50S and above $400 \mathrm{hPa}$ have cooled as have the uppermost regions near $30 \mathrm{hPa}$. The most extensive and largest temperature increases in the solution occur between $15 \mathrm{~S}$ and $30 \mathrm{~N}$ between 800 and $400 \mathrm{hPa}$ with shifts of 2 to $4 \mathrm{~K}$ representing 1 to 2 sigma shifts in mean temperatures! Such shifts are surprising 


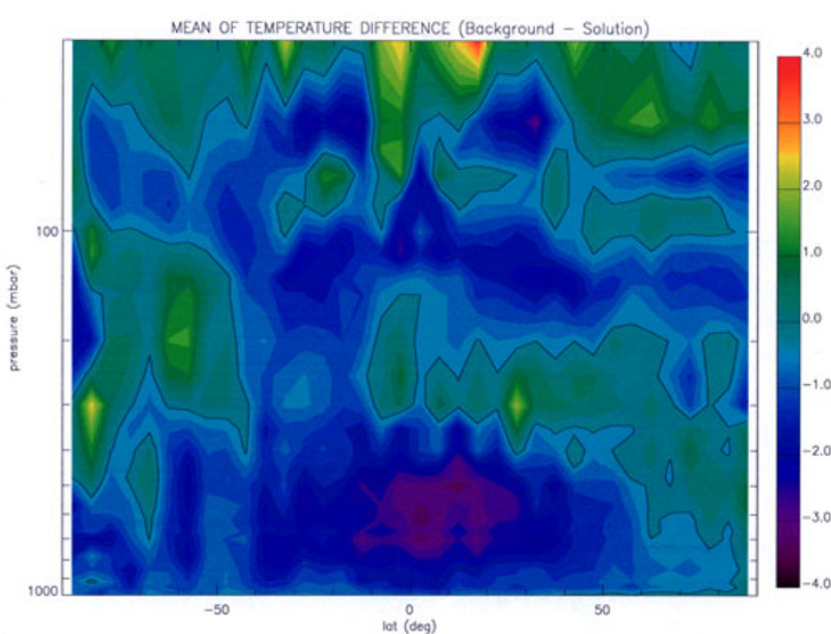

Fig. 5. Latitude and height dependence of zonal mean of Background minus Solution temperatures in Kelvin. The black line indicates the zero difference contour.

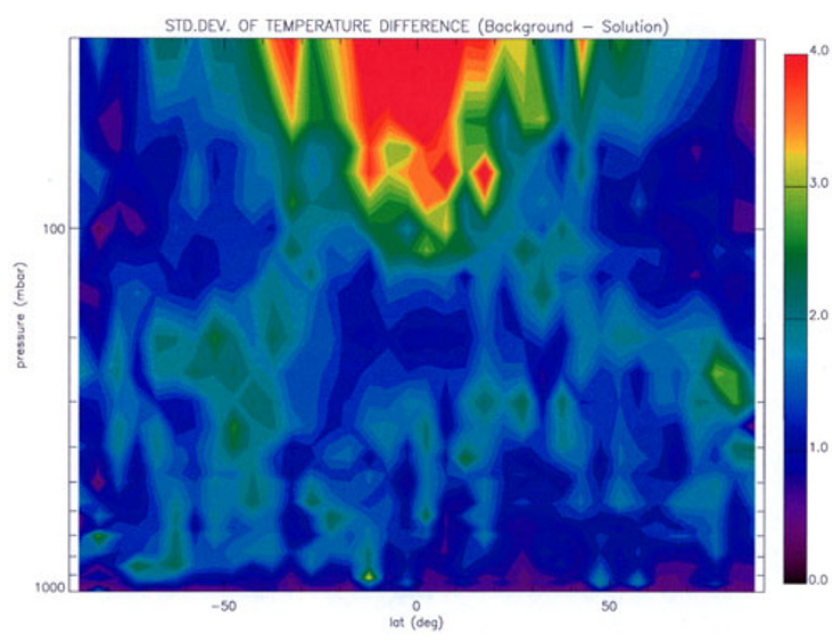

Fig. 6. Latitude and height dependence of zonal standard deviation of Background minus Solution temperatures in Kelvin.

because refractivity should more directly influence specific humidity rather than temperature in warm, wet regions. We believe these changes result indirectly from the lack of water vapor above the $300 \mathrm{hPa}$ level in the model (see Section 5). The low latitude tropopause warming is also a bit surprising and deserves a more thorough examination because we would expect the higher vertical resolution of the GPS results to better capture the extremely cold temperatures at the tropopause than other satellite observations which are assimilated into the analyses. Meridional bands also evident in the mean adjustments in tropospheric and stratospheric temperatures imply the solution is adjusting the temperature lapse rate relative to the background and altering the atmospheric stability.

Near-surface temperatures do not show much change in terms of standard deviation of differences between solution and background temperatures (Fig. 6). Standard deviations in most of the region below the $100 \mathrm{hPa}$ level are in the 1 to

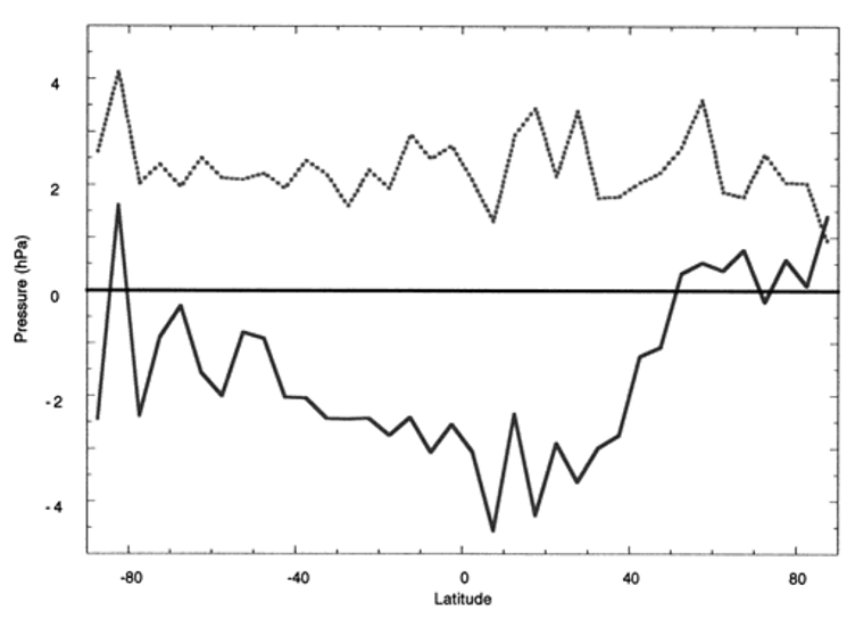

Fig. 7. Latitude dependence of Background minus Solution surface pressure in $\mathrm{hPa}$. Solid line is mean and dashed line is standard deviation.

$2.5 \mathrm{~K}$ range which is reasonable given that the background temperature errors are roughly $1.7 \mathrm{~K}$ (Fig. 3). Standard deviations in the Southern Hemisphere appear to be somewhat larger than their Northern Hemisphere counterparts in general. The region of largest standard deviations of more than $4 \mathrm{~K}$ in the tropical lower stratosphere reflect the large amount of wave activity in this zone which is apparent in the GPS occultations (Kursinski et al., 1996; Kursinski, 1997; Tsuda et $a l ., 1999)$. The 1 to $3 \mathrm{~km}$ vertical wavelengths of these waves are resolved by the GPS occultations but not by operational satellite observations or the ECMWF global analyses. The large variations in Figs. 5 and 6 relative to the background errors in Fig. 3 indicate that the background temperature error covariances should vary with location.

\subsection{DVar surface pressure results}

Figure 7 shows the mean and standard deviation of $\mathrm{S}-\mathrm{B}$ surface pressure difference versus latitude. North of $50 \mathrm{~N}$, the solution has a slightly smaller average surface pressure of about $0.5 \mathrm{hPa}$ than the background generally indicating good agreement where there are relatively many radiosonde observations. South of $45 \mathrm{~S}$, the solution surface pressure is larger than that of the background by 1 to $2 \mathrm{hPa}$. This may reflect a real bias between the analyses and reality but may also reflect the impact of sub-optimal background temperature, pressure and specific humidity error covariances at high southern latitudes. Between $40 \mathrm{~S}$ and $40 \mathrm{~N}$, the solution surface pressure is 2 to $4 \mathrm{hPa}$ higher than the background representing mean shifts in the solution of the order of 1 sigma $(=2.5 \mathrm{hPa})$. The large, mean, low latitude surface pressure adjustments likely result from the lack of model moisture above the $300 \mathrm{hPa}$ level (see Section 5). The standard deviation of the surface pressure differences between background and solution are approximately 2 to $3 \mathrm{hPa}$ which is consistent with the 1-sigma $(2.5 \mathrm{hPa})$ background error estimate.

\subsection{DVar specific humidity results}

Throughout much of the troposphere the solution's mean specific humidity is drier than the background by $20 \%$ or more (Fig. 8) similar to results of Kursinski and Hajj (2000a). Regions of large $\mathrm{S}-\mathrm{B}$ standard deviations in Fig. 9 generally coincide with the large drying regions indicating significant 


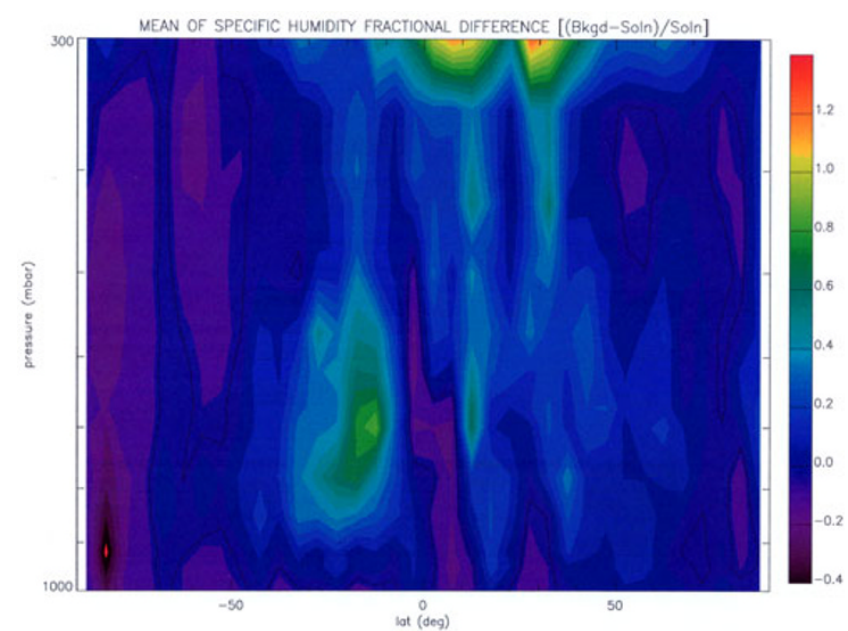

Fig. 8. Latitude and height dependence of zonal mean of Background minus Solution specific humidity in (Background - Solution)/Solution. The black line indicates the zero difference contour.

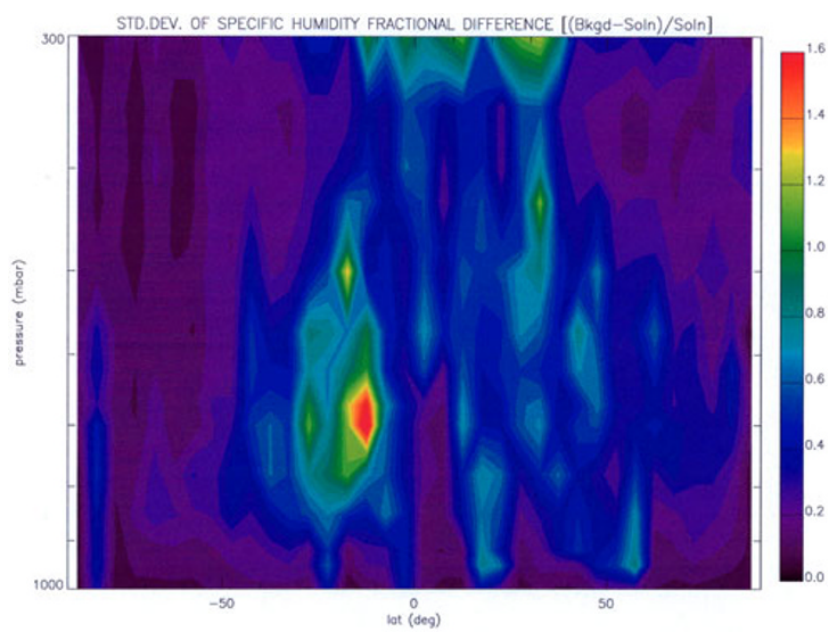

Fig. 9. Latitude and height dependence of zonal standard deviation of Background minus Solution specific humidity in (Background - Solution)/Solution.

disagreement between model and observations in the individual profile structure as well as their average. Drying and standard deviations are very large in the southern subtropics between $5 \mathrm{~S}$ and $30 \mathrm{~S}$ and 900 and $500 \mathrm{hPa}$ reaching a peak near $15 \mathrm{~S}$ and $700 \mathrm{hPa}$ consistent with the systematic rounding off of the very sharp PBL top in this area by the background analyses (Kursinski and Hajj, 2000a). Large discrepancies close to $300 \mathrm{hPa}$ near the latitudes of the Inter-Tropical Convergence Zone (ITCZ) and Indian-Asian monsoons are likely related to the solution attempting to reconcile the sharp model cutoff in moisture above the $300 \mathrm{hPa}$ level with the observations which have no such cutoff (Section 5). The 10-20\% moistening of the solution at high southern latitudes is surprising given the low specific humidities there. The $20 \%$ moistening near the ITCZ below $500 \mathrm{hPa}$ amid drying in the surrounding regions reflects closer agreement between the model and observed refractivities in this region and probably also reflects some influence from the lack of model moisture

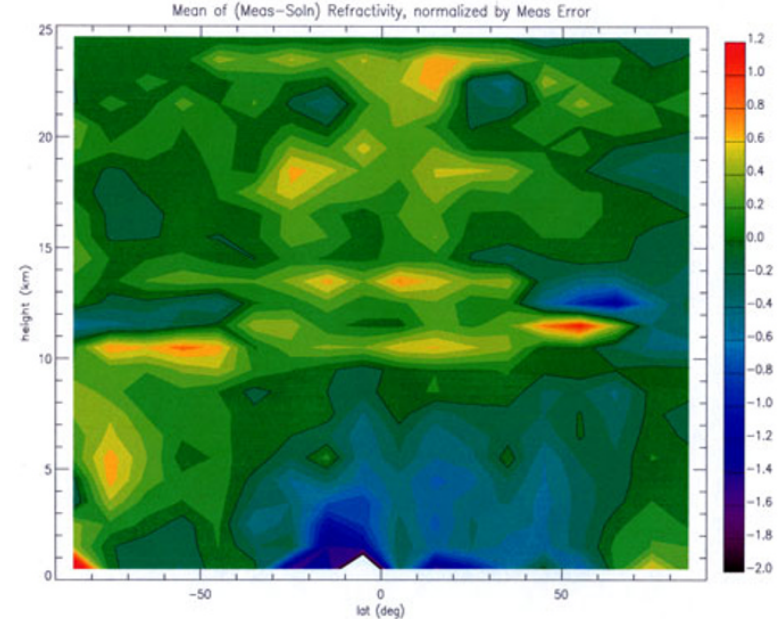

Fig. 10. Latitude and height dependence of zonal mean of Observation minus Solution refractivity normalized to the a priori observational refractivity errors defined in Fig. 2. The black line indicates the zero difference contour.

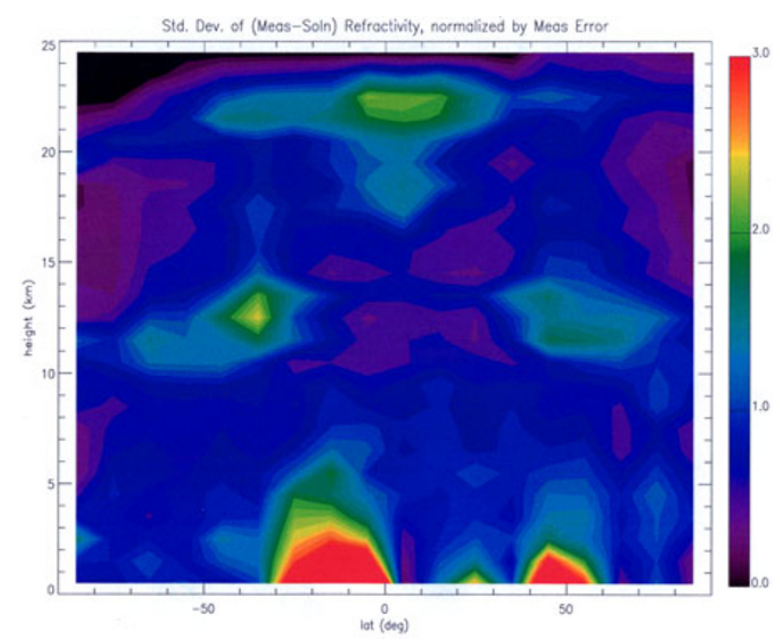

Fig. 11. Latitude and height dependence of zonal standard deviation of Observation minus Solution refractivity normalized to the a priori observational refractivity errors defined in Fig. 2.

above $300 \mathrm{hPa}$ (Section 5).

\subsection{Consistency of the measurement and solution re- fractivity structure}

Figures 10 and 11 show the mean and standard deviation of the differences between the solution and observed refractivities versus height (not pressure) relative to the measurement error covariance. North of $40 \mathrm{~S}$ and below $8 \mathrm{~km}$, the solution refractivity is generally larger than observed and smaller than the background refractivity. This significant refractivity difference between the observations and ECMWF analyses has been interpreted by Kursinski and Hajj (2000a) as a moist bias in the ECMWF analyses in this region, particularly in the southern subtropics within a few kilometers of the surface. At higher altitudes and latitudes, there are sharp changes in color (red to blue) in Fig. 10 near $12 \mathrm{~km}$ in the Northern and $11 \mathrm{~km}$ in the Southern Hemispheres near regions of relatively high standard deviation in Fig. 11, that 
may reflect unresolved tropopause structure in the ECMWF analyses. Above $9 \mathrm{~km}$ at low latitudes, the solution tends to have less refractivity (lower densities) than observed. In the tropical, lower stratosphere, measurement minus solution standard deviations are larger than 1 sigma likely indicating that the solution was unable to fully represent the waves observed in the occultations to within the 1 sigma refractivity errors in Fig. 2. This probably indicates the background temperature errors are too small and the vertical resolution in the ECMWF analyses is too coarse in this region.

\section{Impact of No Model Water above $300 \mathrm{hPa}$}

In the 1D model, water vapor extends from the surface to $300 \mathrm{hPa}$ while specific humidities in the real world extend above the $300 \mathrm{hPa}$ level. In the tropical and monsoonal zones, specific humidities at these levels can be $0.5 \mathrm{~g} / \mathrm{kg}$ or more (Kursinski and Hajj, 2000a), and contribute more than $1 \%$ in refractivity. To compensate for the missing water vapor refractivity, the solution must increase the dry density above the $300 \mathrm{hPa}$ level ( $\sim 9.5 \mathrm{~km}$ altitude) by increasing the pressure at these heights and decreasing the temperature between $300 \mathrm{hPa}$ and $200 \mathrm{hPa}(\sim 12 \mathrm{~km}$ altitude). To increase hydrostatic pressure at a given altitude, the solution increases temperatures at lower altitudes and increases the surface pressure under the background error covariance constraints. Figure 12(a) shows a crude representation of the low latitude $\mathrm{S}-\mathrm{B}$ temperature difference in Fig. 5. With a $\mathrm{S}-\mathrm{B}$ surface pressure difference of $3 \mathrm{hPa}$ (Fig. 7), the resulting solution density at $9.5 \mathrm{~km}$ is greater than the background by a bit more than $1 \%$, roughly the required compensation amount (Fig. 12(b)).
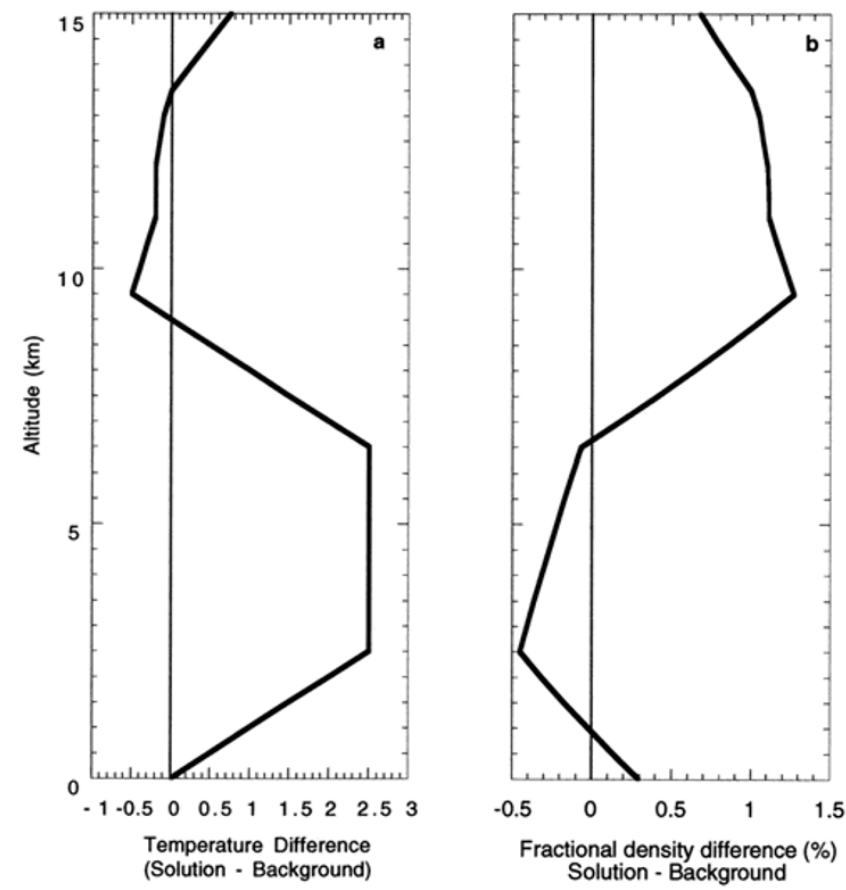

Fig. 12. Simple model of low latitude adjustment in the solution to compensate for lack of water above $300 \mathrm{mb}$. (a) Temperature difference (Solution - Background). (b) Fractional density difference (Solution - Background).
Features consistent with our hypothesis include 1) the sign change in the temperature bias near $300 \mathrm{hPa}$ in Fig. 5, 2) the coincidence between the meridional extent of large temperature modifications in Fig. 5 and high humidities associated with the tropical Hadley circulation, 3) the coincidence of small S - B temperature differences south of $15 \mathrm{~S}$ and the very dry subsidence zones in the subtropics and 4) the large, negative $\mathrm{S}-\mathrm{B}$ specific humidity differences near $300 \mathrm{hPa}$ at $5 \mathrm{~N}$ and $20 \mathrm{~N}$ in Fig. 8 which are likely due to the overestimated dry densities just below $9.5 \mathrm{~km}$ altitude as represented in Fig. 12(b). The large hydrostatic modification of densities peaked at $9.5 \mathrm{~km}$ in Fig. 12(b) also makes the solution's results at higher altitudes somewhat suspect.

\section{Impact Summary}

The impact of the observations on the solution is reflected in the mean and standard deviations of the solution minus background differences, the contribution to the penalty function and the improved error covariance of the solution. Because of the imperfect error covariances and lack of moisture above $300 \mathrm{hPa}$, some care must be taken in interpretation and drawing conclusions.

The improvement to the error covariance implicit in Eq. (3) reflects background and measurement error covariances and $\mathrm{K}$, the gradient of the observations vector with respect to the model state. Improvement here is estimated as the square root of the variance of the solution divided by the variance of the background for the diagonal terms of the error covariance.

Temperature Improvement: The reduction of the background temperature error in Fig. 13 ranges from very little near the surface to a factor of $\sim 10$ near $250 \mathrm{hPa}$. The largest improvement near $250 \mathrm{hPa}$ where $\sigma_{\mathrm{Tsol}} / \sigma_{\mathrm{Tbac}}$ is $10-15 \%$ reflects the large error assigned to background temperature estimates at this altitude associated with the altitude of the tropopause at summer mid-latitudes. The temperature error improvements decrease below the $300 \mathrm{hPa}$ level due to increasing water vapor at lower altitudes. Southern Hemisphere temperature improvements are also greater below 300 $\mathrm{hPa}$ reflecting the large moisture contrast associated with the winter-summer hemisphere asymmetry.

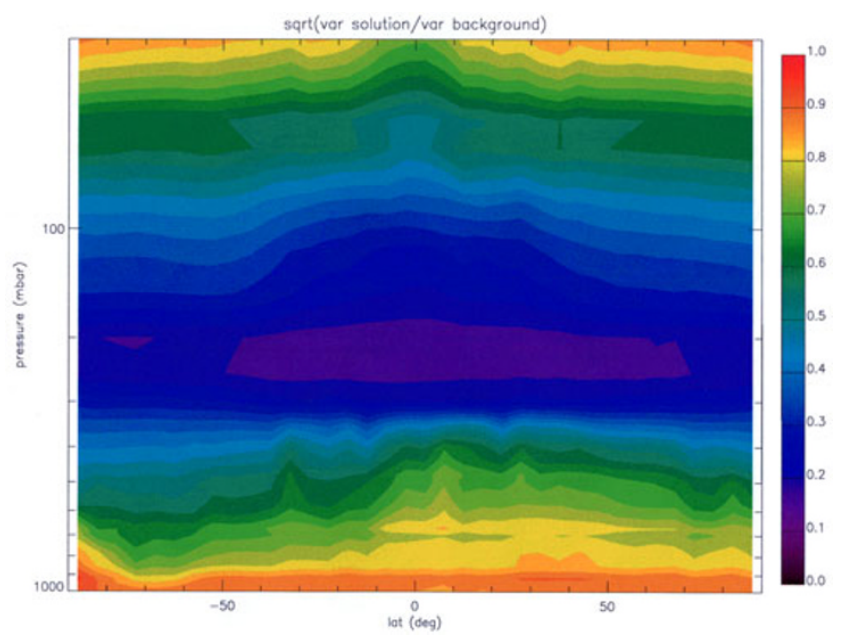

Fig. 13. Temperature error reduction $\left(\sigma_{\text {Tsolution }} / \sigma_{\text {Tbackground }}\right)$. 
Surface Pressure Improvement: The new pressure error estimate is 20 to $25 \%$ smaller than the background error estimate with relatively little dependence on latitude except close to the South Pole (Fig. 14). This cannot reflect the whole story because there should be a larger improvement in areas of sparse observations where the background surface pressure uncertainty must larger. Again the background error covariance needs to vary with location to reflect weaker knowledge in poorly observed areas.

Specific humidity Improvement: The specific humidity error in large regions of the troposphere was reduced to less than $60 \%$ of the background error (Fig. 15). The $Q$ error reduction reaches a maximum in the mid-troposphere near the ITCZ where the solution error is less than $20 \%$ of the background error. The biggest disappointment is in the southern subtropics where the relatively small error reduction does not reflect the large mean adjustments in Fig. 8 and substantial discrepancies between the background and solution moisture estimates there in Fig. 9. The reason is the global error covariance in Fig. 4 does not reflect the systematic ECMWF

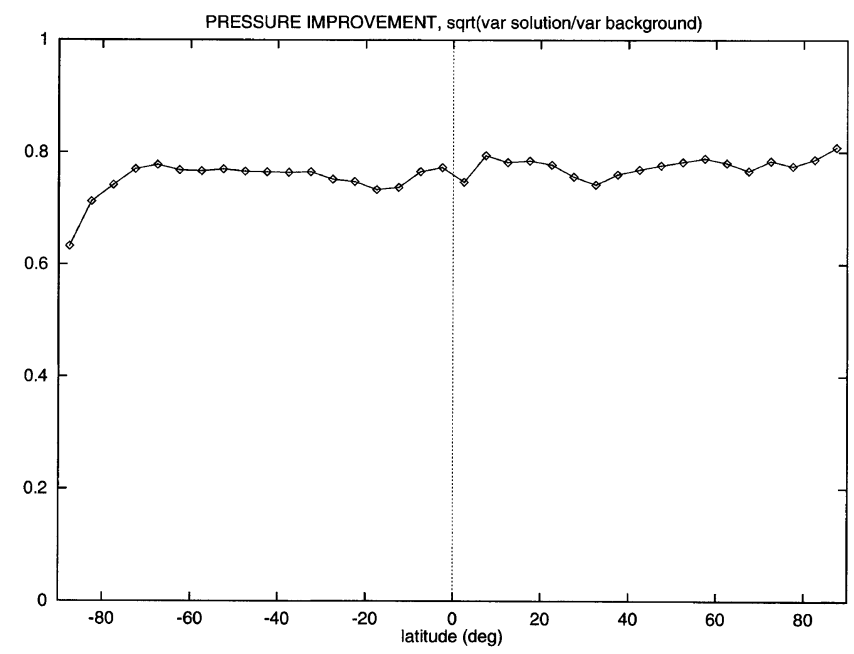

Fig. 14. Surface pressure error reduction ( $\left.\sigma_{\text {Psolution }} / \sigma_{\text {Pbackground }}\right)$.

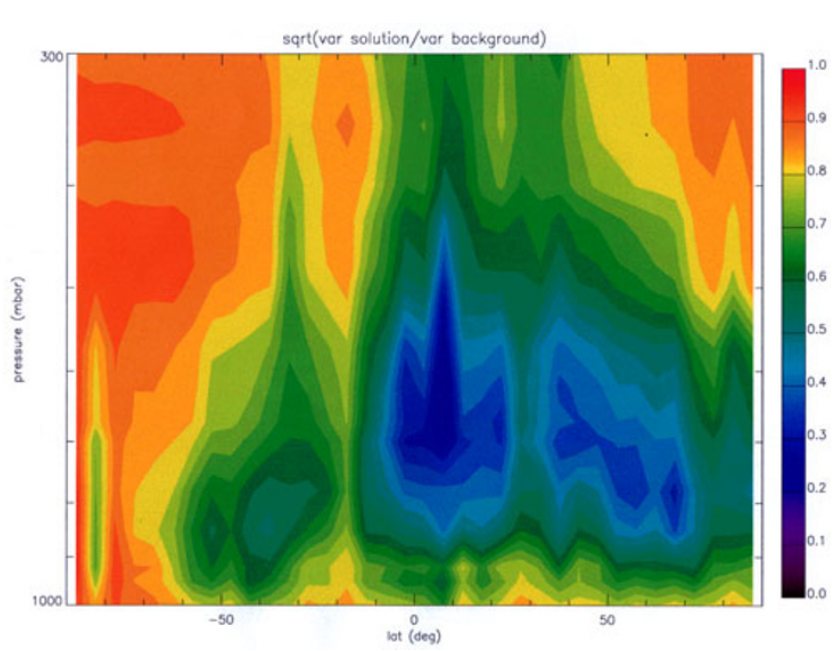

Fig. 15. Specific humidity error reduction $\left(\sigma_{\mathrm{Q} \text { solution }} / \sigma_{\mathrm{Qbackground}}\right)$. analysis errors in this region. There are signs that a weaker version of the same problem is occurring near $30 \mathrm{~N}$. Regarding the general impact on Southern Hemisphere moisture, Kursinski and Hajj (2000b) found the ECMWF analysis specific humidity errors in the Southern Hemisphere to be significantly larger than their Northern Hemisphere counterparts (Fig. 16). Their estimate of the reduction of the background moisture error (Fig. 17) is therefore somewhat larger than that in Fig. 15 in the Southern Hemisphere. Overall the GPS constraints should significantly improve the quality of global moisture analyses.

The magnitude of the penalty function provides some indication of the success of the 1DVar. The value of the penalty function achieved here, when normalized by the degrees of freedom ( $=$ the number of free parameter in the model), is roughly 4 times larger than optimal implying the solution reflects agreement between the background and observations more at the 2-sigma rather than 1-sigma level. Given the simplicity of the error covariances which contain no latitudinal dependence and the simple exponential decay refractivity

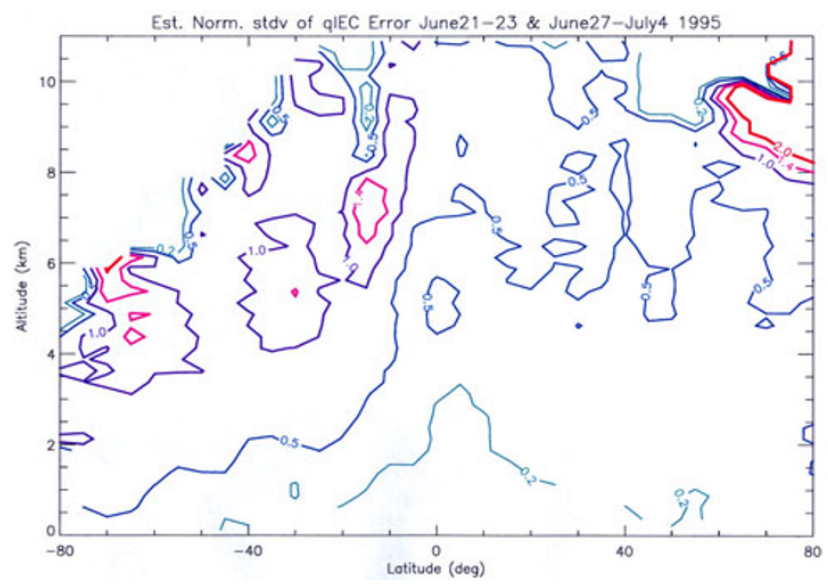

Fig. 16. Estimated fractional error in ECMWF global specific humidity analyses derived via comparison with GPS results (from Kursinski and Hajj, 2000b).

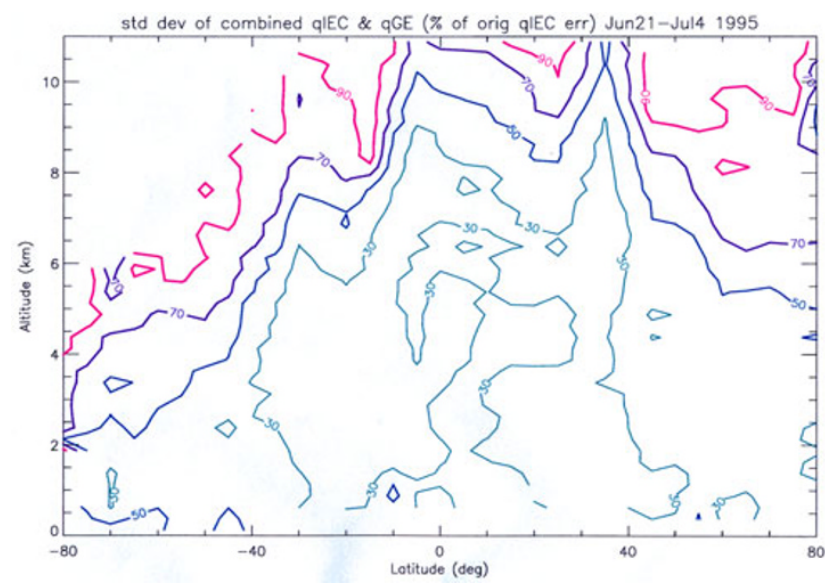

Fig. 17. Expected reduction in ECMWF global specific humidity analysis errors $\left(\sigma_{\mathrm{w} / \mathrm{GPS}} / \sigma_{\text {prior }}(\right.$ in $\left.\%)\right)$ when GPS occultation data is assimiliated Contours are in \%. (from Kursinski and Hajj, 2000b). 
covariance with diagonal terms taken from Kursinski et al. (1997), these initial results described here are encouraging.

Acknowledgments. The authors gratefully thank the GPS/MET program at UCAR for providing the GPS occultation data used in this research. Sean Healy is partially funded by the European Union CLIMAP project (ENV4-CT97-0387). Kursinski and Romans are supported by NASA's Calibration and Validation (Cal-Val) Program.

\section{References}

Fjeldbo, G. F., V. R. Eshleman, and A. J. Kliore, The neutral atmosphere of Venus as studied with the Mariner $\mathrm{V}$ radio occultation experiments, Astron. J., 76, 123-140, 1971.

Gadd, A. J., B. R. Barwell, S. J. Cox, and R. J. Renshaw, Global processing of satellite sounding radiances in a numerical weather prediction system, Q. J. Roy. Met. Soc., 121, 615-630, 1995.

Healy, S. B. and J. R. Eyre, Retrieving temperature, water vapour and surface pressure information from refractive index profiles derived by radio occultation: a simulation study, Q. J. Roy. Met. Soc., 2000 (in press).

Karayel, E. T. and D. P. Hinson, Sub-Fresnel-scale vertical resolution in atmospheric profiles from radio occultation, Radio Sci., 32(2), 411-423, 1997.

Kursinski, E. R., The GPS radio occultation concept: theoretical performance and initial results, Ph.D. thesis, Calif. Inst. of Technol., Pasadena, 1997.

Kursinski, E. R. and G. A. Hajj, A comparison of water vapor derived from GPS occultations and global weather analyses, J. Geophys. Res., 2000a (in press).
Kursinski, E. R. and G. A. Hajj, Zonal variability and accuracy of water vapor estimated from GPS and global weather analyses, J. Geophys. Res., 2000 b (submitted).

Kursinski, E. R., G. A. Hajj, K. R. Hardy, L. J. Romans, and J. T. Schofield, Observing tropospheric water vapor by radio occultation using the Global Positioning System, Geophys. Res. Lett., 22, 2365-2368, 1995.

Kursinski, E. R., G. A. Hajj, W. I. Bertiger, S. S. Leroy, T. K. Meehan, L. J. Romans, J. T. Schofield, D. J. McCleese, W. G. Melbourne, C. L. Thornton, T. P. Yunck, J. R. Eyre, and R. N. Nagatani, Initial results of radio occultation observations of Earth's atmosphere using the Global Positioning System, Science, 271, 1107-1110, 1996.

Kursinski, E. R., G. A. Hajj, K. R. Hardy, J. T. Schofield, and R. Linfield, Observing Earth's atmosphere with radio occultation measurements using GPS, J. Geophys. Res., 102(D19), 23429-23465, 1997.

Kursinski, E. R., G. A. Hajj, S. S. Leroy, and B. Herman, The GPS radio occultation technique, Terrestrial, Atmopsheric and Oceanic Sciences (TAO), 11, 53-114, 2000.

Leroy, S. S., Measurement of geopotential heights by GPS radio occultation, J. Geophys. Res., 102, 6971-6986, 1997.

Rocken, C., R. Anthes, M. Exner, D. Hunt, S. Sokolovskiy, R. Ware, M. Gorbunov, W. Schreiner, D. Feng, B. Herman, Y.-H. Kuo, and X. Zou, Analysis and validation of GPS/MET data in the neutral atmosphere, $J$. Geophys. Res., 102, 29849-29866, 1997.

Tsuda, T., M. Nishida, C. Rocken, and R. H. Ware, A Global Morphology of Gravity Wave Activity in the stratosphere revealed by the GPS occultation data (GPS/MET), J. Geophys. Res., 1999 (submitted).

E. R. Kursinski (e-mail: erk@cobra.jpl.nasa.gov, kursinsk@atmo. arizona.edu), S. B. Healy, and L. J. Romans 